\title{
O INDÍGENA COMO USUÁRIO DA LEI: UM ESTUDO ETNOGRÁFICO DE COMO O MOVIMENTO DA LITERATURA INDÍGENA ENTENDE E USA A LEI No $11.645 / 2008$
}

Edson Dorneles de Andrade (Edson Krenak) ${ }^{1}$ (D)

RESUMO: Este artigo demonstra como o movimento indígena contemporâneo lançaluz sobre a múltipla teia de relacionamentos entre os povos indígenas e a sociedade brasileira. A discussão irá responder à pergunta: como atores indígenas fizeram uso da Lei $\mathrm{n}^{\circ} 11.645 / 2008$ para atuar como agentes sociais fora de seus espaços tradicionais? Para tanto, fiz uso de uma abordagem metodológica de perspectiva indígena decorrente de minha experiência como observador e participante do movimento indígena conduzido pela caravana Mekukradjá, um projeto para disseminar a literatura indígena no Brasil. Essa discussão possibilita ver os indígenas não somente como objetos da lei, mas como sujeitos atuantes do próprio direito.

Palavras-chave: Protagonismo indígena. Literatura indígena. Aplicação da lei.

\section{Indigenous people as users of the law: an ethnographic study on how the movement of indigenous literature understands and uses Law No. 11.645/08}

ABSTRACT: This paper shows how the contemporary indigenous movement clearly demonstrates the multiple

\footnotetext{
${ }^{1}$ Universidade de Viena - Viena (Wien), Áustria. E-mail: edsonkrenak@gmail.com DOI: 10.1590/CC0101-32622019217105
} 
network of relationships between indigenous peoples and the Brazilian society. The discussion will answer the question: How did indigenous actors use Law No. 11.645/08 to act as social agents outside their traditional fields? In order to do this, a methodological approach was used from an indigenous perspective derived from my experience as an observer and participant in the indigenous movement led by the Mekukradja caravan, a project to disseminate indigenous literature in Brazil. This discussion enables us to see indigenous people not only as objects of the law, but also as subjects of their own right.

Keywords: Indigenous protagonism. Indigenous literature. Law enforcement.

\section{COMEÇO DE CONVERSA}

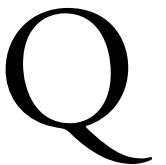

uando saímos de casa, de nossa aldeia, de nosso bairro, de nossa cidade e de nosso país, é necessário mais do que motivação para mudar nossa condição de espectadores, observadores do espetáculo incerto do mundo para participantes ativos nesses novos espaços, especialmente se você é parte de uma minoria, como eu, que luta por reconhecimento, respeito e sobrevivência. Para isso são necessários oportunidades e recursos diversos. Neste texto vou compartilhar como um grupo de escritores e artistas indígenas fez isso, ou seja, saiu da condição de expectador, do estado de espera, para uma atuação promissora e, usando um jargão moderno, "de sucesso". Falo especialmente da caravana Mekukrajá e o advento da Lei no 11.645/2008 (BRASIL, 2008) em escolas e outros espaços públicos de alguns estados brasileiros.

Os indígenas esperam e lutam para que se cumpram as leis concernentes a eles. Como nos lembra Baniwa (2016), as populações indígenas eram invisíveis, inexistentes, desconsideradas em sua identidade e diferença cultural. Assim, Baniwa (2016) afirma:

Ocorre que, à época, aos olhos das políticas públicas, ali não havia índios. Todas as populaçôes eram consi- 
deradas rurais. As escolas, os professores e os alunos, embora todos fossem falantes de suas etnias indígenas, eram denominados e tratados como rurais (BANIWA, 2016, p. 16).

Como ocorreu com muitos Krenak e outros povos quando o Estado dissolveu suas aldeias ou as cidades às incorporaram, as famílias que não fugiram ou foram removidas para outras aldeias ficaram vivendo na roça. Por desconsideração à sua particularidade cultural, foram transformadas em "brasileiros", tiveram suas identidades e culturas apagadas.

Espera-se que o Estado proteja e viabilize os direitos constitucionais e internacionais ratificados pelo país. Mas aqui vamos analisar como os indígenas pararam de esperar pelo Estado e passaram a atuar como usuários de seus direitos, valendo-se de ferramentas jurídicas. Vou chamar de conversa este artigo, porque faz parte de uma pesquisa mais ampla, na qual analiso o imaginário jurídico de alguns povos indígenas do Brasil e como isso aparece em sua literatura, narrativas e outras expressóes artísticas. Quando explicar mais adiante, você, leitor, vai perceber um movimento pendular no estilo do texto. Isso não é gratuito. Embora meu leitor seja o desta revista científica - daí certa formalidade - , quero falar especialmente com o leitor indígena, o acadêmico indígena - daí certa informalidade, que nos caracteriza quando nos encontramos. A flexibilidade estilística faz parte das "metodologias indígenas"; como sabemos, produzimos e compartilhamos conhecimento. Vou explicar mais detalhadamente o que entendo por "metodologias indígenas" a seguir.

O sistema que operou no Brasil em relação aos povos indígenas pode ser comparado ao fenômeno chamado por Edward Said (1978) de orientalismo. Said (1978) discute a relação particular entre Grã-Bretanha e França e o Oriente, relação essa caracterizada por dominação, reestruturação e institucionalização do outro como subalterno ou até mesmo inexistente. Essa operação de tornar o outro marginal, vulnerável e inexistente dá-se no uso das instituiçóes (Estado, lei, ciência, religião, literatura, história etc.), cultura popular (literatura, música, vestuário, entre outros) e a escola tendo papel fundamental (SAID, 1978). Embora o que mais tenha ocorrido no fenômeno des- 
crito por Said (1978) seja distorção, exagero e deturpação da imagem do outro, no caso dos povos indígenas a violência é mais aguda, pois sistematicamente se tentou apagar esses povos, não integrar ou assimilar somente, mas desfazer sua existência.

Somente agora a sociedade brasileira tem a oportunidade de ouvir e ver os povos indígenas falarem sobre si, sobre o que pensam dos brasileiros, o que querem, o que fazem e, principalmente, do desejo de muitos desses povos da floresta de participar da sociedade brasileira sem comprometer sua cultura (BANIWA, 2016), ou seja, rejeitam as políticas de assimilação e integração e propóem uma política de participação. Infelizmente, ainda há lugares nos quais o indígena não está somente em silêncio, mas invisível e, em certa medida, inexistente. Perceber essas realidades é crucial para construir uma sociedade maduramente democrática e mais dinâmica.

$\mathrm{O}$ artigo divide-se em três partes. A primeira discutirá alguns aspectos do movimento indígena brasileiro nos últimos dez anos, enfatizando questóes epistemológicas, sociais e políticas do movimento. Destacam-se, em seguida, algumas ideias do imaginário jurídico indígena, sua relação com os setores da sociedade brasileira no contexto da Lei no 11.645/2008, sob a luz do conceito de "usuário do Direito" (DESMET; BREMS, 2014). Por fim, analiso as experiências da caravana Mekukrajá como um dos exemplos de sucesso, convergindo as duas primeiras partes.

\section{METODOLOGIAS INDÍGENAS}

O método é a maneira de saber ou de fazer as coisas, mas também a maneira de ser. Assim, não há um só método indígena de produzir conhecimento, mas muitos, porque existem diferentes povos indígenas. No campo da ciência, por exemplo, os métodos são presumidamente neutros do ponto de vista ético, porém pode-se usar o mesmo método para produzir algo "bom ou ruim". Alguns são melhores, outros são eticamente polêmicos, como a dissecação e o uso de animais em pesquisas, por exemplo. O que há de comum a muitos povos indígenas no Brasil e fora do Brasil é que as "metodologias de fazer ou saber" são as mesmas 
“metodologias de ser”. Em outras palavras, saber, fazer e ser é a trindade que define a identidade indígena, sua cultura, sua relação com a natureza, o conhecimento, a arte, a cozinha e a literatura. Na ciência ocidental não indígena, algo bem diferente pode ocorrer. Por exemplo, tenho uma amiga vegetariana que trabalha numa empresa de agropecuária. Ela produz remédios para animais que serão abatidos para o consumo. Conheço outra pessoa que estuda teologia, mas é ateia; outro é um político que fala e defende ideias progressistas sobre como melhorar a sociedade, mas na prática não fará nada. $\mathrm{Na}$ perspectiva indígena, esses são problemas causados por "metodologias de saber e fazer" dissociadas do "ser".

Para os indígenas, coletar, colher, plantar, pescar, caçar e até mesmo conversar são açóes de um estado de ser, ser-parte do todo. As literaturas que escrevemos, as narrativas que contamos, as histórias que cantamos revelam não apenas nossas ideias, mas também nossos seres, nossa identidade, nossa relação com o mundo. Assim, os três pontos cruciais das "metodologias indígenas", ou seja, nossas maneiras "de ser, de saber e de fazer", funcionam como um tripé, um sustentáculo do movimento indígena, de sua produção cultural (conhecimento tradicional) e científica (tradução do conhecimento cultural). Essa exposição das metodologias indígenas é uma tentativa de aproximação com povos tradicionais de outros lugares, não somente do Brasil, mas da Austrália, chamados genericamente de aborígenes, do Canadá, como os conhecidos first nations, os Maori da Nova Zelândia, entre outros (SHAWN, 2008; SMITH, 2012).

Outro aspecto relevante dessas "metodologias", especialmente quando tentamos traduzir, é a questão da autoria coletiva. Em muitos momentos esse texto se esforçará em deixar o aspecto individual, uniforme, de transmissão das experiências aqui compartilhadas em direção a uma voz coletiva. Para isso, quando usar o pronome plural "nós", quero dizer que o texto é literalmente resultado de uma roda de conversa (uma festa, um encontro) ou um bate-papo em alguma rede social da internet, quando seria impossível referenciar uma só pessoa. Pois, apropriar-se desses saberes, dessas palavras como se fossem inteira ou parcialmente minhas não seria coerente com as metodologias indígenas aqui utilizadas. Ontologicamente postulamos um sujeito que não pode se distanciar do seu objeto, por ser esse o próprio sujeito, que nunca está sozinho. Ele é uma comunidade (SHAWN, 2008). 
Como pesquisador indígena devo perguntar: qual é minha responsabilidade com o que ouço, aprendo e recebo de minha comunidade e de meus parentes indígenas? Não estou tomando seus conhecimentos e publicando-os como meus; estou compartilhando como costumamos fazer quando saí(a)mos para colher frutas, alimentos ou caçar, trocar bens, negociar. Revelar nosso método é o mínimo que se pode fazer nesse contexto para prestar contas do conhecimento que é gerado e compartilhado.

Esse método ajuda a proteger quem somos. Assumir um nome brasileiro, cortar os cabelos como os brasileiros fazem e passar a morar na cidade são maneiras, formas de sobrevivência. Povos indígenas não deixam de ser quem são ao usar coisas e métodos não indígenas. Embora seja resultado da violenta e sistemática remoção dos povos tradicionais de suas terras, para muitos foi a única maneira de sobreviver (conforme aconteceu com a minha família). Neste texto, minha consciência do estilo acadêmico requer que eu siga certos parâmetros. Farei isso, mas não deixarei de expor o desenho e o compromisso ético indígena de anunciar a multiplicidade de vozes autorais e a centralidade dos relacionamentos pessoais que permeiam meu texto.

Se eu escrevo um texto que é claramente gerado após inúmeros encontros com os mestres, pajés, caciques e outras pessoas de nossos povos, não posso fazer o mesmo que muitos pesquisadores fizeram, deixando um rastro de frustração, desapontamento e injustiça — sem discutir o plágio, a apropriação indevida do patrimônio imaterial etc. Não pretendo "fazer-está-feito", porque o relacionamento que tenho é mais importante do que o conhecimento; e se o faço, nosso relacionamento sofrerá, haverá desconfiança, receio, presunção e traição em nosso relacionamento.

Num primeiro momento parece ser um empreendimento muito amplo, mas estudando as questóes históricas, as necessidades e os desafios sociais e os movimentos dos povos indígenas dos três países acima citados, as semelhanças e as aproximaçóes parecem vir à tona de maneira natural: o passado colonial e as consequências da colonização, a resiliência e a sobrevivência de sua identidade, cultura e tradiçôes, assim como a relação holística e profunda com a terra, demonstrada especialmente nas histórias e narrativas que exemplificam essa relação territorial em detrimento do tempo. Esses três aspectos aproximam as histórias dos povos indígenas em todo o mundo. 
Diferentemente da ciência ocidental, cujo centro científico e cultural é a Europa, responsável por difundir uma epistemologia homogênea e homogeneizante, que descredencia outras formas de saber, ser e fazer, a ciência indígena pressupóe a convivência. A ciência ocidental construiu seu método a partir de premissas com escalas mais ou menos hierárquicas e valorativas, usando a intuição e a dedução, o conhecimento lógico, o conhecimento empírico baseado sobretudo na experimentação e não na experiência. Por fim, produz um tipo de conhecimento autoritário, cujo sujeito ocuparia um lugar de poder, prestígio e sua fala teria "força de lei". O conhecimento indígena está sempre disposto a ir até as últimas consequências para proteger a vida, em todas as suas formas, pequenas e grandes, frágeis e fortes, pois são partes de uma mesma teia da vida, de uma mesma cultura humana. O que houve com os conhecimentos e as metodologias indígenas? Não é difícil imaginar.

Os processos colonizadores são tão poderosos que não somente devastaram povos e regióes do mundo desde o século XV, mas criaram uma forma hegemônica poderosa de epistemologia, de ciência, provocando o quase desaparecimento de outros tipos de conhecimentos, gerando um desequilíbrio global que afeta não somente as pessoas, povos e culturas, mas todo o planeta. A partir de uma leitura de Boaventura de Souza Santos (2014) é possível afirmar que a epistemologia ocidental tem sido uma máquina de operação colonial, capitalista e patriarcal, cujo método de exploração e silenciamento do outro é também sua forma de produzir conhecimentos e riquezas. Os inúmeros avanços da ciência ocidental não devem ser descartados, mas criticados em sua maneira de ser, fazer e transformar o mundo. Pensando alternativamente, as metodologias indígenas aqui propostas buscam "decolonizar" a maneira como as pessoas veem e leem os povos indígenas, oferecendo outras perspectivas também válidas.

\section{PROTAGONISMO INDÍGENA E A LEI}

A experiência do Brasil e de outros países com a Lei, com o Poder Judiciário, reflete um pouco essa epistemologia centralizadora. Quando as velhas estratégias de dominação dos povos indígenas come- 
çaram a falhar — genocídio, assimilação e integração — , por conta da resiliência e resistência de muitos desses povos, desenvolveu-se uma imagem bastante irreal e desvalorizada do indígena como indivíduo tutelado. Digo desenvolveu-se porque essa imagem é refletida tanto no Estatuto do Índio de 1973 como no Código Civil Brasileiro de 1916, revelando sua profunda coerência com a visão dos conquistadores dos séculos precedentes. Nesse sentido, o indígena era qualquer coisa, menos um ser humano; incapaz diante da lei, do rei e da fé, necessitava de alguém para advogá-lo, representar, falar por ele.

As reservas indígenas, áreas de terras reservadas e protegidas, por exemplo, são uma conquista, mas acabam sendo interpretadas também como tentativas de isolar esses seres considerados "incapazes de se proteger", porque a ideologia dominante do Estado não respeita o direito do diferente. Por isso, os indígenas vêm assumindo uma posição bastante ativa nas últimas décadas para reverter esse quadro ${ }^{2}$.

Como fazer isso sem comprometer sua cultura, identidade e história, isto é, sem necessariamente deixar-se assimilar? Para que faça sentido sua atuação na sociedade brasileira, para ambos os lados, a estratégia é trocar experiências, traduzindo ideias e narrativas nos dois sentidos: na comunidade indígena e na comunidade brasileira. Nesse sentido, a promulgação da Lei $\mathrm{n}^{\circ} 11.645$, em 8 de março de 2008, que estabelece a inclusão no currículo oficial da rede de ensino a obrigatoriedade da temática "História e cultura afro-brasileira e indígena", se tornou uma oportunidade de compartilhar quem somos, o que sabemos e como nos relacionamos com a sociedade. Em vez de continuarmos nas páginas dos livros didáticos como figuras e referências do passado, entraríamos nas escolas e outras instituições de ensino do país como agentes vivos e "ao vivo" de transformação social (BANIWA, 2013; 2016).

Mudou nossa relação com as leis e os direitos indígenas, que dependia dos mediadores, advogados, juízes, promotores e outros agentes sociais. A citação da lei passou a fazer parte do nosso discurso, do enforcement, do empoderamento de açôes afirmativas a partir do nosso ponto de vista. Para certos setores da sociedade não era suficiente citar a Constituição — que ainda nos reserva um lugar à parte no Brasil — ou a Declaração das Naçóes Unidas sobre os Direitos dos Povos Indígenas 
(DNUPI), que reconhece nossa liberdade e o direito de autogoverno, autodeterminação, entre outros. A lei em questão passou a fazer parte de certa negociação. Nessa mesa de negociação não há mais juristas ou advogados, mas "usuários"3 (DESMET, 2014).

Neste artigo procuro seguir de perto a proposta de Desmet (2014), na qual a perspectiva tanto do usuário dos direitos humanos (no meu caso, da lei) como sua trajetória são importantes para descrever e analisar um escopo maior da experiência social. Nossa proposta é, pois, analisar não somente o aspecto da experiência com a Lei no 11.645/2008, mas uma trajetória de luta e compreensão jurídica. A análise é feita, portanto, na perspectiva humana, indígena, não do instrumento jurídico impessoal burocrático do Estado com suas camadas institucionais - advogado, corte, processo etc. Não analisamos a Lei ou os direitos humanos, mas como as pessoas experenciam esse direito. Desmet (2014, p. 4) afirma:

In other words: instead of analysing a human rights issue from the viewpoint of a lighting technician, who chooses one particular spotlight or colour to illuminate the scene (thus inevitably leading to a partial picture), one adopts the position of the actor or musician on the scene, who is simultaneously illuminated by different lights, from different perspectives and with different strengths and colours. It concerns knowledge "from within", an insider's perspective based on the experience of effective engagement with human rights, instead of knowledge produced from the vantage point of an omniscient narrator ${ }^{4}$.

No entanto, embora a autora defina de maneira mais estrita o "human right user", implicando uma relação substitutiva ou até representativa, na qual alguém calça os pés de outro (a metáfora é dela), aqui faço uso de uma experiência etnográfica do termo, dentro de uma perspectiva indígena.

Seguindo Brems e Desmet (2014), a proposta de classificação de usuários dos direitos humanos prescreve quatro níveis: requerentes, 
cumpridores, apoiadores e juristas ou usuários forenses (advogados, promotores, juízes, por exemplo). Esse aporte permite a adoção de uma análise mais harmoniosa com a perspectiva indígena, pois se considera o ponto de vista do usuário - do indígena, neste caso - ao invés de focar em um ponto particular do Direito, da lei ou da filosofia jurídica dos direitos humanos.

O estudo etnográfico demonstra que o contexto dos usuários, em detrimento do técnico ou do jurista, é crucial para a evolução das leis e da sociedade, especialmente uma sociedade como a brasileira, que ainda se nega a admitir sua malha multicultural, multiétnica e plurilinguística. O usuário aqui é o indígena, embora se possa discutir a escola, o negro, o professor, os alunos/estudantes, entre outros como usuários dos direitos humanos. A complexidade dos aspectos legais e sociais da implementação de uma lei e principalmente dos direitos humanos confronta o usuário com uma realidade quase impossível de mudar ou superar, em termos de problemas, soluçóes, desafios, tradução e compreensão dos chamados ditames da lei, pois, desde o ponto de vista constitucional e democrático, o que parece ser simples e claro para os povos indígenas é um verdadeiro martírio de espera, discussão, luta e realização para gozar, enfim, do direito que a lei implementa.

Isso significa que o indígena não é o alvo/objeto da lei ou dos direitos humanos como se fosse um paciente enfermo, no qual a ciência médica aplica seus recursos para curá-lo, mas um agente, um ator que atua para fazer valer seu direito, luta para encontrar sua maneira de aplicar a lei num espaço que - a saber — não lhe é dado, mas tomado em negociaçóes nem sempre justas ou pacíficas e nunca completas. A incompletude da negociação entre o usuário do direito indígena e a sociedade que supostamente oferece esse direito é permanente.

Para atender a uma tentativa didática de descrever o termo, posso afirmar que existem quatro níveis do uso da lei $i^{5}$. O primeiro nível é quando o indígena "invoca a lei”, ele necessita ter acesso às instituições, como escolas e universidades. O segundo é quando a lei é usada para "descrever e legitimar seu discurso" dentro dessas instituiçóes. O terceiro nível é quando as instituiçôes são ajudadas por agentes indígenas a aplicar/obedecer/seguir a lei. E por fim, o último nível é 
quando o Estado - fonte autoritária da lei - recebe o indígena, sua experiência e ação para "aperfeiçoar a lei” (veja a Figura 1).

$\mathrm{Na}$ Figura 1, criada por mim, as setas internas mostram um movimento interno e ascendente dessa experiência e sua relação com as instâncias hierárquicas da sociedade brasileira, já as setas maiores externas indicam que o movimento se recicla e à medida que se desenvolve, identifica novas maneiras de usar a lei.

O último nível, de baixo para cima, é claramente uma situação menos comum, mas que já se vê em muitos lugares, por exemplo em Minas Gerais com Ailton Krenak, no Amazonas com Ely Macuxi e Gersem Baniwa, no Nordeste com Graça Graúna. Todos atuam diretamente em políticas públicas ou cargos públicos, sua esfera de atuação dispensa a passagem pelos níveis anteriores (GRAUNA, 2013). No entanto, dadas a complexidade dos cargos políticos e sua ampla esfera de atuação, a aproximação com a Lei no 11.645 se fragmenta e enfraquece com diferentes e diversificadas demandas ${ }^{6}$.

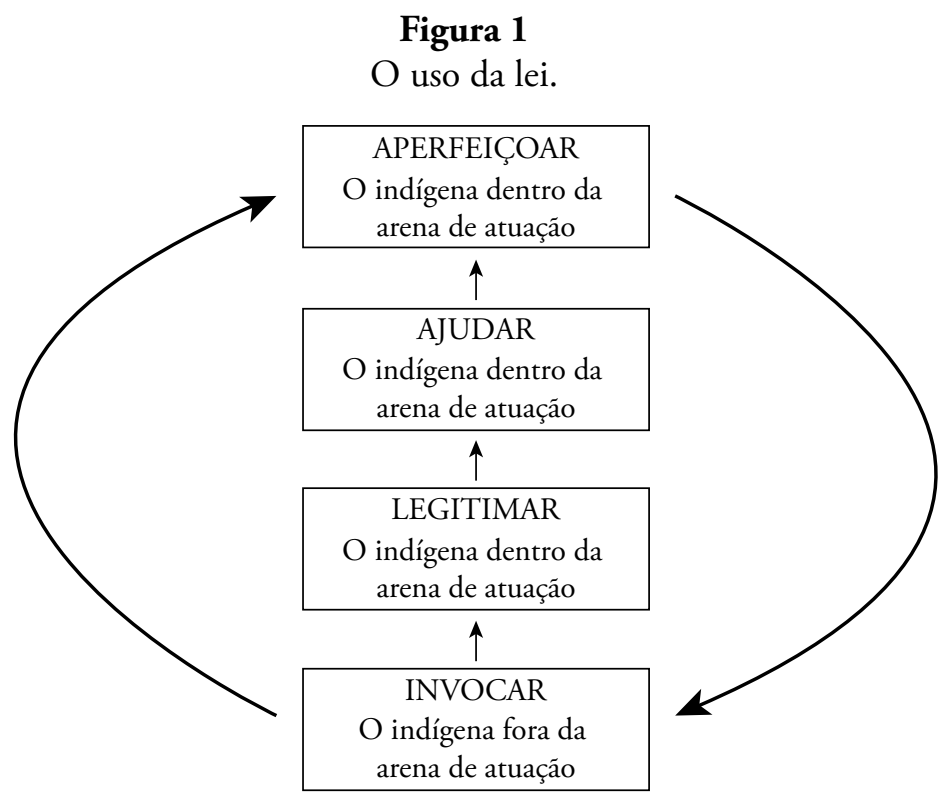


O cenário em que tal lei se insere para os povos indígenas é visto dentro do amplo contexto de outros mecanismos nacionais e internacionais de reconhecimento dos direitos dos povos indígenas, como a Constituição de 1988, a Declaração das Naçóes Unidas dos Povos Indígenas (ONU, 2008) e a Organização Internacional do Trabalho (OIT) no 169 (2011), que tratam não somente dos aspectos intrínsecos e particulares desses povos, mas especialmente de sua liberdade e proteção em relação à sociedade que os circunda, a brasileira.

Esses mecanismos não são uma mensagem aos povos indígenas. É um memorial para a própria sociedade brasileira de que ela não é a primeira protagonista nessas terras, nem mesmo está sozinha no espaço democrático chamado Brasil. São ferramentas de proteção para o Estado, para corrigir e não repetir os erros históricos da colonização. O Estado que fundamenta esse mecanismo deve proteger-se a si próprio de ser um autor de injustiças (DESMET, 2014). Nós indígenas, apesar do discurso que nos insere como objetos dos direitos, somos cooperadores e donos do nosso próprio destino.

Diferentemente de muitos outros contextos globais, nos quais a relação dos povos indígenas com o Estado é bastante conflituosa e renhida, no Brasil, apesar de todo o histórico de violência e da persistente invisibilidade desses povos, a relação se caracteriza por uma contínua busca de harmonia, negociação, respeitosa inclusão e busca de compreensão e legitimidade ${ }^{7}$.

No entanto, ainda falta a muitos líderes e povos indígenas visualizar o que pode ser feito tendo em vista a lei. Muitos estão ainda passivos, ou sua visão está viciada na espera de açôes por parte do Estado e da sociedade brasileira. Numa entrevista, Gersem Baniwa, um dos mais importantes líderes indígenas no Brasil, responde à pergunta "Em que medida a aprovação dessa lei favorece o desenvolvimento de políticas públicas voltadas para o ensino da História e cultura afro-brasileira e indígena?" desta maneira:

A Lei $n^{\circ} 11.645$ fortalece as políticas públicas voltadas para os povos indígenas já existentes, e 
em médio e longo prazo pode ampliá-las, aperfeiçoá-las e mesmo qualificá-las na medida em que torna as questóes indígenas e afro-brasileiras mais visíveis e adequadamente mais conhecidas. O desconhecimento ou o falso conhecimento, assim como a indiferença com relação a esses segmentos sociais e étnicos vigentes na sociedade brasileira, sempre foram as principais causas da ausência de políticas públicas coerentes e adequadas a eles. Cidadãos, planejadores e gestores mais bem informados acerca das realidades e demandas dos referidos segmentos sociais terão mais sensibilidade e compromisso com os seus direitos e mais qualificados para pensar, criar e implementar políticas públicas para eles (BANIWA, 2016, p. 20).

Assim, meu interesse é mostrar como nossas experiências (minha e a do grupo de escritores e artistas indígenas) no campo, isto é, em escolas, universidades e institutos, lançam luz sobre a lei, reforçam os direitos e fortalecem nossa identidade.

Ao final indicamos como essa experiência aponta caminhos de aperfeiçoamento dos mecanismos legais de direito e aplicação da lei, como institucionalizar a presença indígena nas escolas e universidades, por exemplo por meio de planos de carreiras, inclusão de professores e formadores indígenas, criação de disciplinas e linhas de pesquisa conduzidas e relacionadas por e para pesquisadores indígenas. $\mathrm{O}$ protagonismo indígena passa, portanto, pela porta dos mecanismos democráticos de participação efetiva na sociedade.

\section{O MOVIMENTO INDÍGENA BRASILEIRO}

Embora alguns autores, como Sá (2004), considerem que somente nos últimos 20 anos o movimento indígena tem alcançado um nível maior de organização, o fato é que os indígenas, para sobreviverem e chegarem ao século XXI, usaram diversas formas de organização de enfrentamento, negociação e resistência desde a conquista no século XVI. Citado em Sergio Cohn, Ailton Krenak reitera: 
A existência de um movimento indígena organizado não é novidade na história da Brasil. Quando Cuñambembe formou a Confederação dos Tamoios, em 1535, e reuniu todos aqueles povos para enfrentar os portugueses no litoral, ele estava sentindo a necessidade de estabelecer algum tipo de relaçáo com quem estava chegando, para que as coisas não ficassem tão no ar (KRENAK apud COHN, 2015, p. 123).

O movimento literário indígena, por sua vez, alcança um status política e culturalmente mais profundo, caracterizado menos por uma releitura das publicaçóes feitas por antropólogos, linguistas e viajantes, e mais por criação e proteção dos seus direitos autorais, identidade e reapropriaçáo do conhecimento tradicional. Resumidamente, decolonizar o discurso literário a respeito do indígena pelo direito à autoafirmação/determinação.

\section{MAS O QUE É A LITERATURA INDÍGENA?}

Ainda hoje quando se fala em literatura indígena nas instituições de ensino (escolas e universidades) a reação geral de muitos professores é de certo estranhamento e desconforto. Não se tem conhecimento suficiente sobre o assunto e muito do que se sabe é oriundo de informaçóes equivocadas, incompletas e insuficientes. Mas essa realidade está mudando acentuadamente. Isso ocorre devido a três fenômenos que vou abordar nesta parte do texto: o surgimento de interessantes pesquisas na área da literatura indígena nas universidades; o ensino de cultura e literatura indígena tanto nas escolas como em universidades, que tem ampliado e saído das cadeiras de antropologia (que tem seu inestimável valor) e do folclore (que tem seu dispensável valor); e, por fim, um movimento de escritores e pensadores indígenas, assim como apoiadores da causa indígena, cientistas e outros interessados que têm trabalhado bastante para que isso ocorra.

A literatura indígena representa um desafio para os estudos literários, linguísticos e textuais dentro da academia. Os conceitos e regras estéticas, performáticas e linguísticas aplicados ao texto canônico da 
literatura brasileira não são facilmente aplicados à literatura indígena. Isso porque o sistema literário indígena é outro, sua razão de existir (sua história) é outra, embora use o sistema da indústria cultural (autor, livro e leitor) como meio de difundir-se, clama interna e externamente por outros padróes, outros critérios de avaliação.

Vemos, por um lado, engajados na literatura indígena, autores não indígenas, por exemplo, Maria Silvia Cintra Martins (em texto como "Inscrições, narrativas e literatura de produção indígena", de 2012), Stephen Hugh-Jones em "Escrever na pedra, escrever no papel" (2012), Janice Thiél em Pele silenciosa, pele sonora: a literatura indígena em destaque (2012) e Lynn Mario Menezes Souza em "Uma outra história, a escrita indígena no Brasil”, de 2008, que propóem ampliar a concepção de código e de texto, portanto de literatura, ressaltando as características multimodais, multigráficas (contra a equivocada ideia do agrafismo), multidiscursivas, das literaturas da floresta. Esses autores, a maioria professores universitários, sinalizam para um crescente, rico e diversificado campo de pesquisa, inserido nos chamados estudos disciplinares, que vem costurando diversas áreas do saber, tais como a literatura, artes, música e dança. Mais do que nunca o Brasil pode ver aqui um caldo formidável de produção de conhecimento. Quando as bases do formalismo e do estruturalismo foram abaladas quase que simultaneamente nos anos 1960 pelo pós-estruturalismo e outros "ismos", o conceito de texto também foi alargado, mas isso é outra discussão que não vou aprofundar neste artigo.

Por outro lado temos as organizaçóes (coletivas por natureza) indígenas e suas produçóes literárias, a exemplo das Organizaçóes Indígenas do Rio Negro (FOIRN), que publicara, entre muitos o texto coletivo "Antes o mundo não existia" (KUMU; KENHIRI, 1980), do Instituto Indígena Brasileiro para Propriedade Intelectual (INBRAPI), criado em 2002, com o Concurso de Escritores Indígenas - Prêmio Tamoios, que desde 2003 premia e lança no mercado escritores indígenas contemporâneos e o menos burocrático e mais acadêmico movimento indígena, Caxiri na Cuia, cuja publicação, em quatro volumes da revista LEETRA, destaca o esforço da tradução do pensamento indígena para a sociedade brasileira, na forma de um intenso diálogo, cujos tópicos principais são: história e literaturas indígenas feitas pelos próprios, a busca por ancestralidade, o resgate e o fortalecimento da identidade étnica e cultural. 
Esses movimentos de dentro e fora das comunidades, com orientação "decolonizadora" de compreensão e difusão do saber indígena, despertaram novo interesse acadêmico: a pesquisa da literatura nativa. Estudos sobre essa temática no Brasil (o que pode ser constatado também em países tão diferentes como Canadá, México e Austrália) revelam que escritores indígenas (nascidos em aldeias, florestas, entre outros) se apropriam da língua do colonizador, aqui "aportuguesa”, para traduzir a alma, a cultura e a literatura indígena. Através dessa nova linguagem escrevem contos, poemas, romances, autobiografias e até ensaios, seguindo a tradição do múltiplo: multigêneros, multimodais, multidiscursivos, multilinguagens, multiautoral.

Esse novo tipo de literatura brasileira, a indígena - cujas metodologias e pesquisas serão discutidas no tópico posterior, Caravana Mekukradjá - está presente principalmente nas escolas e instituiçóes culturais, mas também em eventos voltados para o público infantojuvenil. Por quê? Porque professores, não contentes com o 19 de abril, têm pesquisado a literatura indígena, trabalhado com escritores indígenas e editoras, que publicam as obras, a fim de criar um ambiente literário mais rico e diversificado nas escolas. Algumas políticas públicas têm apoiado também a promoção e distribuição desses livros.

Nas universidades, igualmente, podemos encontrar inúmeras dissertações de mestrado e teses de doutorado, algumas defendidas por pesquisadores indígenas, tais como Graça Graúna, através do texto "Contrapontos da literatura indígena contemporânea no Brasil" (2013), Eliane Potiguara e suas reflexóes em Metade cara, metade máscara (2004) e Daniel Munduruku na tese $O$ caráter educativo do movimento indígena brasileiro (1970-1990) (2008), fortalecendo essa primeira dobra da pesquisa em literaturas indígenas.

As editoras também têm explorado esse renascimento (na língua do colonizador) ou renovação (em novas maneiras de narrar) da voz indígena como um interessante nicho mercadológico. Elas têm contratado ilustradores exímios para ilustrar os livros, compondo uma verdadeira obra de arte multimodal, numa interessante toada com o acento nativo. Um excelente trabalho, diga-se de passagem, que editoras, governo, agentes culturais e escritores indígenas têm feito para colocar em pauta a literatura indígena. Há cem anos Mariátegui (1988) afirmava não existir, 
mas um dia, existiria com força... Veja por exemplo o movimento das águas e do tempo na capa do livro de Daniel Munduruku (2007), ilustrado por Maurício Negro; o sincretismo (texto verbal e imagético) busca dialogar com suas origens da floresta e da aldeia.

O professor da educação básica (educação infantil, ensino fundamental e ensino médio) descobrirá nesses aspectos abordados (largamente discutidos em nosso livro Literatura indigena: modos de usar, a ser lançado em breve) um riquíssimo repertório de ideias para o ensino de língua, história e cultura indígena, conforme obriga a Lei no 11.645/2008. Rediscutir a história do Brasil, nossos laços indígenas, a questão da terra, do meio ambiente, da ideia de progresso são outras implicaçóes dessa literatura. Isso porque a pesquisa com a literatura indígena não se restringe à universidade.

Além desses aspectos que se relacionam com a história e cultura do Brasil, o professor encontrará na literatura da floresta informaçóes sobre como vivem os povos indígenas, no que creem, tipos de alimentação, música, religião, filosofia, entre outros assuntos. A escola tem também oportunidade de explorar outros vieses; temos visto interessantes trabalhos com a matemática indígena, a astronomia, gastronomia e medicina dos pajés. Conhecimentos tradicionais que há muito têm entrado para os anais científicos, porém infelizmente pouca credibilidade foi dada às fontes originárias desse material.

Não obstante, diante disso a ponte entre a pesquisa e o ensino é facilmente construída. Entáo perguntamos: por que se deve ensinar literatura indígena? Como? Existem muitos motivos, mas creio que podemos citar somente dois. O primeiro, e menos conhecido, é o estatuto histórico da literatura brasileira. A literatura brasileira nasceu da literatura europeia, especialmente portuguesa, com influência francesa e inglesa (veja os modelos dos nossos maiores literatos, por exemplo, Machado de Assis e José de Alencar). Ela se desenvolveu, tornou-se um sistema autônomo e a academia a colocou no rol dos clássicos - um repositório da história e da cultura de uma nação ou de "nações”. O problema é que essa história não é tão simples. Tal literatura foi criada e desenvolvida principalmente para informar, imaginar e rotular - com isso dominar, colonizar - outros povos. A literatura europeia trazida para o Brasil mostrava o quão melhor era a vida na 
metrópole, e a literatura produzida aqui para os europeus lerem servia para mostrar o quão pobre e sem cultura viviam os povos d'além mar, o quão esses povos precisavam de um rei, de uma lei e de uma fé, pois, coitadinhos não tinham nada...

Isso explica porque as expressóes nativas foram marginalizadas, apagadas e quase destruídas por completo (BANIWA, 2013). Esse combate ideológico empreendido pela colonização explica nossa história. Tratar disso é conhecer nossas raízes, explicar nossos problemas; é entender nossa cultura, nos ver em um espelho mais nítido. Somente assim podemos resgatar de maneira justa, sem estereótipos e injustiça, o lugar dos povos nativos dessas terras d'além mar.

O outro motivo (entre outros) é que os alunos devem ser capazes de aprofundar o conhecimento de seu país e apreciar a contribuição contínua dos povos indígenas, não somente para o Brasil, mas para toda a América Latina. A prioridade no ensino de literatura indígena é a compreensão das formas de vida indígena, interpretar sua maneira de estar no mundo, sua relação com a terra, com as tradiçóes, e fruir as expressóes artísticas, respeitando-as em sua diferença.

O resgate, o respeito e a promoção dessa literatura são garantidos por leis nacionais e internacionais, como afirma o artigo 23 da Constituição Federal, "são reconhecidos aos índios sua organização social, costumes, línguas, crenças e tradiçóes, e os direitos originários sobre as terras que tradicionalmente ocupam, competindo à União demarcá-las, proteger e fazer respeitar todos os seus bens" (BRASIL, 1988). Também na Declaração das Naçóes Unidas o artigo $3^{\circ}$ afirma:

Os povos indígenas têm o direito de conservar e reforçar suas próprias instituiçôes políticas, jurídicas, econômicas, sociais e culturais, mantendo ao mesmo tempo seu direito de participar plenamente, caso o desejem, da vida política, econômica, social e cultural do Estado (ONU, 2008).

Assim como declaram os artigos $2^{\circ}$ e $5^{\circ}$ da Convenção no 169 da OIT: 
Os governos deverão assumir a responsabilidade de desenvolver, com a participação dos povos interessados, uma ação coordenada e sistemática com vistas a proteger os direitos desses povos e a garantir o respeito pela sua integridade. [...] Essa ação deverá incluir medidas: a) que assegurem aos membros desses povos o gozo, em condiçóes de igualdade, dos direitos e oportunidades que a legislaçáo nacional outorga aos demais membros da população; b) que promovam a plena efetividade dos direitos sociais, econômicos e culturais desses povos, respeitando a sua identidade social e cultural, os seus costumes e tradiçóes e as suas instituiçóes (OIT, 2011).

A proteção e o desenvolvimento da cultura indígena são garantidos por essas leis e regimentos que fortalecem nosso sistema jurídico. É importante proteger e assegurar a vida e as expressóes dos povos tradicionais, mesmo que em minoria.

Para que isso ocorra na sociedade brasileira, a população deve se envolver. Assim sendo, destacamos o terceiro ponto deste artigo: o trabalho. O trabalho táo bem feito por atores sociais e outros profissionais da cultura. Destacamos aqui as açóes dos escritores indígenas Ailton Krenak, Kaká Wera, Olivio Jekupé, Daniel Munduruku, Cristino Wapichana, Tiago Haiyki, Graça Graúna, Eliane Potiguara, Roní Wasiry Guará, entre outros que, apoiados principalmente pelo Instituto UKA, têm promovido a literatura indígena. Eles têm trabalhado arduamente para a promoção cultural e artística das expressóes ameríndias.

A literatura, como expressão da cultura e dispositivo que comunica e compartilha bens espirituais, intelectuais e estéticos, entra ou opera na sociedade somente por condiçóes bem específicas, as quais o mestre Antonio Candido (2009) já ensinara, a saber: as condições de produção, circulação e recepção. Nas últimas três décadas (desde o início dos anos 1980), escritores indígenas de diversos povos têm mostrado na e pela língua portuguesa uma gama enorme de narrativas indígenas, renovando, recontando, recriando e produzindo a literatura indígena do Brasil. 
É importante destacar que a literatura indígena do Brasil não nasce nesse período. Ela existe há muitos séculos, mas antes era intermediada, conhecida somente por traduçóes e coletâneas feitas por viajantes, escritores não indígenas, linguistas e antropólogos (CANDIDO, 2009). Mas nos últimos anos podemos afirmar que essa literatura é novamente apropriada por seus originais "autores". As condições de produção dessa literatura, assim como a circulação e recepção têm muitos desafios, precisamos aumentar os números de escritores indígenas, treiná-los nas técnicas de tradução cultural e produção em língua "estrangeira" (a língua portuguesa é falada nas comunidades, mas com muitos limites impostos até mesmo pela realidade educacional do Brasil).

Aliás, precisamos ir além das escolas para divulgar nossos livros, fazê-los circular em diferentes espaços, como universidades, departamentos de Letras, institutos de pesquisa, institutos de promoção cultural, centros culturais, livrarias, entre outros. A recepção constitui um desafio a toda produçáo literária, mas acreditamos que o trabalho desenvolvido tem sido um bom caminho, principalmente com os parceiros professores da educaçáo básica, nos cursos de formação de professores, a discussão na mídia e em outros meios adequados. Nosso objetivo é estimular cada vez mais o interesse de novos leitores por essa impressionante literatura ancestral.

Assim, o trabalho do movimento indígena, como mostrado na tese de doutorado de Daniel Munduruku (2008), tem caráter educativo, sobretudo porque busca ampliar o diálogo com a sociedade brasileira. Essa proveitosa interação tem sido vista em espaços como centros culturais, jornadas literárias e concursos literários, caravanas de promoçáo do livro e tantos outros mecanismos de desenvolvimento da cultura escrita. Esse diálogo de caráter educativo visa reensinar às novas geraçóes brasileiras a ler outros textos, outras culturas, outras identidades. Contribuir para uma leitura mais rica, mais humana. A literatura indígena é multicultural, vai além dos textos, convidando a ver outras formas de vidas, diferentes identidades. Ensina a ler o outro para aceitá-lo e comungar com ele - este é o trabalho da literatura indígena.

Considera-se que Marcel Proust, autor do romance Em busca do tempo perdido, escrito em 1908-1909, tenha de certa forma reinven- 
tado a experiência de ler a literatura ocidental. O narrador soberano que ele propóe é, na maior parte do tempo, um desconhecido; o leitor saberá seu nome após ter lido mais de mil páginas; esse narrador mergulha numa reflexão profunda de si mesmo, do processo da escrita, da morte, da passagem do tempo perdido. Usando referências da mitologia europeia, grega e inglesa, Proust (1983) converge o mundo para si mesmo e o leitor junto. A grandeza de Proust para os não indígenas está nisso, segundo minha leitura. $\mathrm{O}$ autor, portanto, representa o narrador onisciente e o leitor onisciente que se assenta confortavelmente em sua cadeira e lê. Um espelhamento completo da leitura.

Por sua vez, a grandeza da literatura indígena para os não indígenas é um convite para olhar o exterior, além do texto. É também uma reflexáo sobre o tempo, o tempo quando animais e seres humanos compartilhavam mais claramente uma mesma cultura, a natureza lhes era diversa e multiforme. Esse movimento, em direção ao outro, propóe uma alternativa de se corrigir o tempo passado, marcado pela violência, colonização e marginalização, e criar um futuro de diálogo e convivência. As referências mitológicas indígenas, o mundo descrito no texto clama por uma redenção: a redenção da natureza, da relação do homem com seu meio. Tanto o narrador quanto o escritor e o leitor são incompletos sozinhos, precisam se encontrar na cena da vida e se iluminarem conjuntamente.

A literatura indígena tem, portanto, múltiplas funçóes, mas a principal é a educacional, sua ação pedagógica tradicional volta-se agora para a educação do outro (MUNDURUKU, 2008). A literatura indígena, assim como outros conhecimentos tradicionais indígenas, tem muito a ensinar, desde que o leitor queira ler, ouvir e aprender. Para o escritor e contador de histórias indígenas, essa literatura é também seu discurso de legitimação, é sua fala. Nessa tríplice dobra, a literatura indígena tem sido um testemunho poderoso da força e da excelência de povos que, apesar de todos os sofrimentos, estáo aqui no século XXI se renovando, enriquecendo e desafiando a sociedade. À medida que esse testemunho é conhecido pela pesquisa acadêmica ou cultural, pelo ensino, seja na educação básica ou na universidade e, também, pelo trabalho abnegado de tantos, a sociedade como um todo ganha. A justiça, o conhecimento e a beleza triunfam. 


\section{LITERATURA E PROTAGONISMO}

$\mathrm{Na}$ tentativa de encontrar nossa vereda nesse caminho macunaímico da sociedade brasileira, mais denso e diverso, mais perigoso e angustiante do que as matas virgens em pleno veráo, a perspectiva metodológica usada aqui é múltipla e interdisciplinar que vê a Lei $n^{\circ} 11.645 / 08$, o direito e movimento indígena como uma arena de negociação (às vezes pacífica e bem-sucedida, pacífica e não bemsucedida, não pacífica e bem-sucedida, não pacífica e malsucedida). Essa negociação, esse espaço social chamado "uso da lei" é culturalmente e socialmente construído e costurado, tomado e conquistado (DESMET, 2014).

Durante esses dez anos da Lei no 11.645 temos enfatizado mais do que nunca nossos direitos, especialmente a respeito do nosso direito de fazer as coisas a nossa maneira: falar, fazer e trabalhar. As formas de ser, fazer e conhecer indígenas estão relacionadas ao artigo $3^{\circ}$ da Declaração das Naçóes Unidas sobre os Direitos dos Povos Indígenas (ONU, 2008), que afirma, os povos indígenas têm direito à autodeterminação. Em virtude desse direito determinam livremente sua condição política e buscam livremente seu desenvolvimento econômico, social e cultural.

Concordo com a interpretação do advogado indígena Noel Pearson (2011) acerca da autodeterminação:

A diretriz para as políticas indígenas no futuro deve ser que os povos indígenas tenham o direito de assumir responsabilidade e poder sobre nossas próprias vidas. Entendido corretamente, a autodeterminação é o poder de assumir responsabilidade, é tomar para si mesmo o poder que por muito tempo foi assumido pelo governo. Indivíduos, famílias, comunidades devem tomar o poder sobre seus próprios destinos (PEARSON, 2011, grifos nossos).

É por isso que o movimento da literatura indígena é tão especial: ao mesmo tempo em que traz para o centro da ação política suas 
narrativas e cultura, assume a responsabilidade de fazer algo em nome ou sob o poder da lei. Ser usuário da lei e dos direitos é, assim, tomar a responsabilidade sobre o próprio destino, sua própria voz, sua própria maneira de falar sobre si.

Sonhamos o dia em que não mais antropólogos e acadêmicos ensinarão sobre os povos da floresta nas universidades, mas os próprios povos da floresta virão e falarão sobre eles. Não mais advogados e juízes não indígenas legislando e julgando nossas causas, mas nós mesmos nos defendendo legalmente, usando as leis tradicionais e da nação a qual temos escolhido nossa nacionalidade por direito. Por esses sonhos, que ações como as da caravana Mekukredjá são conduzidas. Relato-as a seguir.

\section{A CARAVANA MEKUKRADJÁ ${ }^{8}$}

As citações e transcriçóes de conversas a seguir são advindas dos meus memoriais, como anotaçóes de conversas e conferências, contextos formais e informais, caderno de campo e textos desconhecidos dos autores. A melhor maneira de fazer justiça às fontes é citar da forma que segue, pois não tenho a referência específica de onde e quando foram feitas, a não ser o fato de que se trata de acontecimentos do período entre 2011 e 2014. Este é também um gesto coerente com as metodologias indígenas, nas quais a conversa e o diálogo constituem formas outras de elaboração do conhecimento. Das minhas anotações, destaco os diálogos a seguir: "Nós, artistas e escritores indígenas, vivemos na aldeia. [...] Temos diferentes experiências com a sociedade brasileira, mas sempre de tensão, de negociação, de diálogo" (HAK'Y, 2016).

Nem sempre os espaços que nos foi permitido viver e morar pela sociedade dominante, pelo Estado, têm fronteiras e limites claros. Mas por razão das diferentes epistemologias e filosofias de vida, sentimos que estamos distantes dessa sociedade obrigada legalmente a proteger nossos direitos. Isso náo ocorre por muitos motivos, mas o principal deles é a ignorância a respeito de quem nós somos. 
Por essa razão sempre vivemos à margem, à praia, esperamos nos encontrar com o outro para compartilhar e trocar coisas. A visão que temos dos brasileiros não indígenas é de uma sociedade que trabalha demais, sofre demais, tem medo demais, têm coisas demais, e esse "demais" os impede de experimentar a vida de maneira mais profunda, mais ampla e, claro, mais simples. O problema é quando esse "demais" extrapola suas próprias fronteiras em direção aos nossos modos de vida, nossos espaços, nos quais vivemos diferentemente. Quando querem plantar demais, ter gado de corte demais, minas demais, entre outras coisas que ameaçam nossas vidas (HAK'Y, 2016).

Em função disso, por iniciativa de Daniel Munduruku, que vive numa cidade no interior de São Paulo, criamos a caravana Mekukradjá. Nosso objetivo é propiciar à sociedade brasileira a vivência e o contato com autores e artistas indígenas. Não vamos somente aos lugares e organizaçóes não indígenas, visitamos também os parentes e nos reunimos para nossas rodas de conversas sagradas, discutindo nosso presente e nosso futuro.

A palavra Mekukradjá vem de uma língua kayapó que significa transmissão de saberes. A caravana é uma janela, uma fresta que possibilita olhar para nossa gente, para nossa cultura, e perceber que somos contemporâneos, somos humanos, somos parecidos em muitas coisas, embora muito diferentes em outras. Essencialmente, é um testemunho, uma cruzada pacífica para dizer que não somos seres do passado.

[...] A Caravana literária indígena foca no momento presente, no espaço de (con)vivência, na relação cultural e emocional que se dá entre as partes. Não é necessariamente o texto escrito o centro da atenção, mas a relação construída, o jogo, a performance, o ethos negociado, aprendido, transmitido. Não é uma experiência científica, estética ou até mesmo filosófica - não convidamos as pessoas para pensar, mas para "ser conosco" parte de um ritual, de um culto, de uma experiência. 
Não propiciamos experimentos científicos, mas experiências diretas com as culturas tradicionais brasileiras (MUNDURUKU, 2017).

Cristino Wapichana: A caravana é algo em movimento, é uma forma de evangelização às avessas. Nos dispomos a andar pelo Brasil e oferecer à sociedade a nossa diversidade cultural, social e literária. Objetivamos viver melhor, não sozinhos, mas com a sociedade que nos circunda. Cada artista e escritor usa dinâmicas e maneiras próprias dos seus povos, de suas experiências com outros povos indígenas e com a sociedade brasileira. As pinturas corporais criam um ambiente lúdico, principalmente em escolas, onde vestimos as crianças com nossas palavras, histórias e memórias. A contação de histórias ocupa um lugar central nesses encontros, assim como nas aldeias de muitos de nossos povos (WAPICHANA, 2016).

Muitas vezes ouvimos crianças e adultos dizerem coisas sobre sua ancestralidade indígena, às vezes coisas como "minha avó era indígena" ou orgulhosas como "sou descendente de indígenas". "Sabia que minha avó foi pega no laço?". Nesses momentos de confissáo de que a outridade não mais existe, as histórias se transformam em narrativas pessoais, referências que unem a todos num mesmo destino (MUNDURUKU, 2017).

Quando a caravana visita um espaço mais acadêmico ou de reflexão social nos apresentamos como construtores da democracia brasileira, uma democracia verdadeira onde todos, especialmente as minorias, têm voz. [...] A caravana é uma das inúmeras formas que as comunidades indígenas encontram para participar da sociedade que as embraça e protege. [...] Essas histórias que contamos nos conectam com as pessoas mais do que imaginamos, elas também contam suas histórias e experiências. Quase sempre há um elemento de dor e injustiça também. Compartilhamos, nos curamos e, ao final, sentimos que somos todos da mesma aldeia, como discute Bozzoli (1996) a respeito do Apartheid na África do Sul (MUNDURUKU, 2017). 
Um aspecto muito importante da caravana é conectar as comunidades locais com os escritores e artistas da região. Por exemplo, na cidade de São Paulo há parentes morando, mas também há as centenárias aldeias guaranis, espremidas pelo concreto, que continuam ali conservando sua cultura. Quando a caravana, em escolas e outras instituiçóes, fala dessas aldeias e traz para o palco escritores como Olivio Jekupé e Cristino Wapichana, residentes nessas aldeias e na cidade, respectivamente, muitos são "pegos de surpresa", pois em geral não se espera mais aldeias indígenas numa megalópole como São Paulo (JEKUPÉ, 2009).

A Lei $n^{\circ} 11.645 / 2008$ funciona como uma porta de entrada em muitas escolas. Como ainda não há material apropriado para a implementação da lei, a caravana vem com sua criatividade, sua força e dinamismo romper os muros e as paredes das salas de aulas, das escolas, dos centros comunitários das pequenas e grandes cidades do Brasil.

A aplicação dessa lei não é "nenhum presente", é antes de tudo uma vitória "pela luta dos velhos que começou há 300, 500 anos atrás" (MUNDURUKU, 2018). Isso é uma luta muito antiga, e não é nenhum presente. É uma conquista, porque os indígenas nunca conseguiram nada de "mão beijada”. [...] Esse método nos ajuda a fugir do estereótipo, desconstruir o indígena genérico, principalmente dos livros didáticos, da mídia, e da literatura brasileira chamada canônica, a qual é especialmente responsável por uma imagem pretérita do índio como derrotado do processo histórico (MUNDURUKU, 2017).

Portanto, a caravana Mekukradjá ocupa um lugar central para que a literatura brasileira seja relida, para que o cemitério seja sacudido e transformado. $\mathrm{O}$ indígena na literatura brasileira ocupa um espaço de luto, um cemitério, seu corpo e sua terra estão condenados a desaparecer ou se transformar em algum monumento do passado, numa memória distante. $\mathrm{O}$ movimento literário indígena se nega a ser um fantasma do passado, se nega a habitar o lugar do estereótipo do outro "exotizado" ou em transição. Não estamos em transição, estamos em movimento, em transformação das relaçóes com o nosso povo, com os outros povos bra- 
sileiros descendentes de africanos, asiáticos e europeus (MUNDURUKU, 2017).

Paulinho Kayapó: Nossa literatura é nossa pele, nossa roupa, a roupa de nossos corpos que são uma extensão da Terra. Somos nossa terra, nossos lugares sagrados, nossos rios são nosso sangue que corre nas veias do mundo (KAYAPÓ, 2015).

É toda sabedoria que temos e que vem da floresta ou da fonte ancestral. Para nós são saberes memoriais que formam o território sagrado. Envolvendo toda essa sabedoria que está na forma de construir seus símbolos ritualísticos e na medicina que vem da mata., a cura pelas plantas. Mas esses saberes precisam ser protegidos (KAMBEBA, 2018).

Escrevemos em português, publicamos nossa literatura, sim, para sermos reconhecidos e isto está ocorrendo por nosso trabalho e pelo trabalho de apoiadores em escolas, instituiçóes públicas e privadas, empresas e pessoas que divulgam, promovem e compram nossos livros e materiais (KAMBEBA, 2018).

Até a Constituição de 1988 e a Lei no 11.645/2008, os povos indígenas eram tratados como povos em transição à comunidade nacional brasileira. Conforme a observação de Manuela Carneiro da Cunha (1992), éramos considerados seres efêmeros, em transição: transição para a cristandade, para a civilização. As leis e políticas públicas eram um franco ataque à sobrevivência indígena. E o movimento indígena se caracterizou como de defesa, de luta por sobrevivência e negociação com essa mesma sociedade (KRENAK, 2016).

Após 1988 e 2008, apesar das tremendas dificuldades de implementação dessas leis e direitos, apesar do descaso de vários setores da sociedade (responsáveis estatais) em aplicar, garantir e proteger esses direitos, o movimento indígena alcançou um novo rumo, um renovado senso de autoidentificação, de orgulho étnico e valorização de sua cultura (KRENAK, 2016). 
Talvez esse protagonismo em direção à sociedade herdeira dos colonizadores, da chamada sociedade estatal no Brasil, esteja ligado e alimentado pelos ventos da emergência indígena em toda a América Latina - começando pelos zapatistas no México, passando pelo campesinato indígena na Bolívia, as incursóes politicamente violentas dos mapuches no Chile, como demonstra o estudo de Bengoa (2007). Em outras palavras, o protagonismo indígena não é novo. Mas as leis e as visóes de mundo, que sempre os vitimizaram, não lhes tiraram a resiliência e a criatividade necessárias de lutar e defender sua própria história.

O movimento da literatura indígena se caracteriza por "reapropriação" e "reafirmação" de nossa história, tomada pela responsabilidade de viver e compartilhar nossas próprias maneiras de ser, saber e fazer. O tempo em que somente antropólogos e especialistas falavam em nome dos povos indígenas está acabando. As antigas narrativas estão sendo recontadas, recriadas e renovadas à medida que são retomadas como o seu próprio patrimônio.

A classificação mitológica que a antropologia histórica deu às histórias indígenas, suas narrativas, cantos e rituais está sendo relida e reescrita hoje com a inteireza e o poder que o mito, enquanto narrativa de um tempo - passado inacessível — é incapaz de fazer (BANIWA, 2013; MUNDURUKU, 2007). As "narrativas mitológicas" trazem para os espaços contemporâneos a renovação de sua filosofia, de sua religião, de seus costumes, de suas memórias e relaçóes sociais. O mito é incapaz de descrever a contemporaneidade dos seres hiperssociais, multinaturais e multiculturais que são os povos indígenas.

No entanto, há um aspecto dessa literatura que ainda está embrionário: sua capacidade de refletir e refratar a história colonial. Assim como essas histórias tradicionais refletem momentos marcantes que testemunham as mudanças e desenvolvimentos de nossos rituais, cerimônias e relaçóes, a literatura indígena brasileira ainda está para produzir histórias que reflitam o trauma da colonização, do genocídio, do epistemicídio, das remoçôes forçadas, das humilhaçóes públicas, as consequências irreversíveis das políticas de assimilação do Estado brasileiro. 
"O corpo ferido da terra sangrará na pele de nossa literatura logo, logo. Esse espaço vazio de elaboração literária provavelmente ainda espera ser preenchido pela voz que está só começando a falar" (KAYAPÓ, 2015).

\section{PARA FINALIZAR E SUGERIR ALGUNS CAMINHOS}

Pelo que vimos, o uso da Lei no $11.645 / 2008$ pelos povos indígenas nos últimos dez anos representa um passo que vai além da própria lei e Constituição Brasileira, é uma retomada de responsabilidade pelo nosso lugar na sociedade. Sabemos que já temos direitos contemplados na Declaração das Nações Unidas sobre os Direitos dos Povos Indígenas entre outras leis internacionais, mas agora essa lei representa um passo concreto, uma ponte em direçáo à sociedade brasileira.

A experiência de contar histórias nas escolas é uma oportunidade de trazer ou transportar as crianças e professores a um lugar de não conflito, um lugar onde perspectivas sobre a natureza e a cultura convivem numa relação de respeito. Essas convivências com as histórias indígenas são convivências com o indígena. Não é um experimento literário, mas uma experiência social e vital para transformar nossas experiências com o outro que, de repente, se faz conhecido, familiar, parente.

Essa transformação, que ocorre algumas vezes, pode contribuir profundamente para a vivência plena da democracia, onde as diferenças são aparências, pois no fim do dia ou da história somos todos a mesma comunidade. Portanto, ao desenhar o futuro dos povos indígenas no Brasil, três linhas fazem-se absolutamente necessárias: literatura, participação e direitos.

Ao ouvir nossas histórias e saber de nossas culturas, sem o jargão acadêmico da antropologia, sem a capa estereotipada dos livros didáticos, as pessoas percebem que os indígenas vivem como pessoas de qualquer lugar e buscam negociar seus valores na terra onde vivem (BANIWA, 2013; MUNDURUKU, 2008; 2011). A contação de histórias indígenas é uma poderosa ferramenta que nos conecta com a múltipla teia da vida: com nossos ancestrais e 
culturas, preservando nossa identidade; com parentes do Brasil e de outros países que têm na contação de histórias as metodologias que nos identificam uns com os outros; com as sociedades não indígenas, que ouvindo nossas vozes e nossa história podem nos compreender e lutar conosco contra a injustiça, a discriminação e o racismo; com os mestres que lutam contra a predominância do discurso hegemônico de uma só ciência, de uma só maneira de saber, de fazer e de ser. As narrativas despertam nossas identidades múltiplas e nossa natureza plural. Além disso, e em consequência disso, a contação de histórias tem um poder de cura e reconciliação.

Estarmos juntos, contando histórias, nos transforma em uma comunidade, em uma aldeia, nos unifica: o lugar que era do outro, meu, dele, é, no ato de contação de histórias, nosso. Todo o nosso ser é despertado nesse momento: nossa mente, espírito e coração, nossa criatividade, nosso amor, nosso senso de missão e responsabilidade. Como Bozzoli (1998) salienta, a esfera pública das histórias, legitimizada pela lei e pelo consenso, possibilita enfraquecer as ideias distorcidas, os estereótipos que existem, pois trazem para a arena as vozes e narrativas que foram silenciadas. Embora o ritual da contação venha de uma experiência pessoal, não é a "impressão digital individual que a valoriza" e legitima, mas a "marca de uma comunidade que substitua as representaçóes individuais por um espírito coletivo, elevando a experiência pessoal a um compromisso coletivo" (BOZZOLI, 1998, p. 169). A autora pontua ainda que ouvir as histórias de pessoas e comunidades que sofreram e sofrem grandes perdas, injustiça e opressão tem também o poder de transformar as experiências particulares, privadas, em mitos, discursos públicos, fazendo com que essas experiências sejam de todos (BOZZOLI, 1998).

A lei discutida aqui abre um potencial precedente para leis semelhantes, possibilitando redefiniçóes do que entendemos como comunidade, como sociedade. A tomada de responsabilidade é superar a condição da minoria mais vitimizada, marginalizada, empobrecida e violentada no Brasil. Usando a lei que, mesmo tarde, vem para mudar a direção de um sistema que num passado bem recente nos proibiu de falar e aprender nossas línguas, nos removeu de nossas terras, educou nossas crianças em escolas colonizadoras que eliminavam nossa identidade e ignoravam nossos direitos. 
Essa lei conecta nossa ação diária com a Constituição e com os mecanismos internacionais de direitos dos povos indígenas do mundo inteiro que, por sua vez, estão ligados pela triste história e destino, mas trazem em comum a necessidade de tomar sua própria história. Embora respiremos, por vezes, a ideia de que o futuro para os povos indígenas continua incerto (e juntamente o futuro da humanidade), considerando o avanço das formas agressivas e destrutivas de economia e desenvolvimento da sociedade atualmente, sonhamos com um mundo plural.

Pois sabemos que em muitos lugares do mundo a violência militar, política, econômica e cultural contra povos indígenas está bem documentada, no Brasil existe um sistemático esquecimento, uma orquestrada ignorância a respeito do que sofreram e sofrem os povos indígenas. Ainda se experimenta uma grande pressão social e política contra nossa cultura e nosso direito à terra. Por isso a urgência e a necessidade de nosso protagonismo.

Uma pergunta que talvez tenha passado por todo o texto e que tenha sido de alguma forma respondida precisa ser reelaborada aqui: Por que as escolas? Por que uma lei que atinge diretamente o sistema educacional? Porque nada tem sido mais efetivo e mais poderoso para anular e apagar as culturas indígenas ao redor do planeta do que o sistema educacional estatal, nossas ideias, nosso conhecimento, nossa literatura, imagem e existência não são apenas diminuídos ou apagados nos livros e nos currículos. Eles são substituídos por formas de pensar e ensinar, que sistematicamente nos transformam em inexistentes.

A lei é um mecanismo coadjuvante na transformação da sociedade. Somente a ação protagonista dos usuários da lei pode operar mudanças significativas. Por isso, a história indígena no Brasil ainda necessita ser escrita e documentada de forma ampla e profunda para ser usada nas escolas. Uma história indígena que deverá contemplar a experiência pessoal dos contadores de histórias, suas trajetórias pessoais, sua maneira de ler e recontar as narrativas dos seus povos e de sua família (muitas foram removidas e separadas de suas terras tradicionais). Portanto, temos a inclusão de uma variedade de vozes, histórias e trajetórias que precisam ser faladas, revisitadas e documentadas. Isso será completamente cumprido quando, sob a Declaração Universal dos 
Direitos e dos Povos Indígenas e sob o poder constitucional, os povos indígenas desfrutarem de uma vida independente, emancipada e livre.

O campo do direito nos insere numa participação política e democrática que é relativamente nova para nós, povos e descendentes indígenas, visto que estávamos guerreando e fugindo do Estado, ou vivendo às custas de uma débil proteção. Ao começarmos a ganhar experiência em ativa participação política, devemos aprofundar nossa compreensão dos direitos e das leis. Assim como os princípios cerimoniais e as tradiçóes protegeram nossa cultura e nos conduziram até aqui. A sede de justiça deve continuar nos guiando rumo ao futuro. O sistema político brasileiro deve providenciar e esperar oportunidades permanentes de protagonismo indígena nas casas dos homens designados deputados e senadores, por exemplo ${ }^{9}$, a fim de deixarmos de ser usuários da lei para ser, como diz a tradição, legisladores de nossos próprios caminhos e escolhas.

\section{REFERÊNCIAS}

BANIWA, G.J. dos S. L. A história e cultura indígena no contexto da Lei 11.645/08: reflexos na educação brasileira. Revista de Educação do COGEIME, Manaus, v. 25, n. 49, p. 11-23, 2016. http://dx.doi.org/10.15599/2358-9299/ cogeime.v25n49p11-23

BANIWA, G.J. dos S. L. Educação para manejo do mundo: entre a escola ideal e a escola real no Alto do Rio Negro. Rio de Janeiro: Contracapa/Laced, 2013.

BENGOA, J. La emergencia indígena en América Latina. México: FCE, 2007.

BOZZOLI, B. Public Ritual and Private Transition: the Truth Commission in Alexandra Township. African Studies, Cape Town, v. 57, n. 2, p. 167-195, 1998. https://doi.org/10.1080/00020189808707894

BRASIL. Código Civil de 1916. Brasília: Senado Federal, 1916.

BRASIL. Constituição da República Federativa do Brasil. Brasília: Senado Federal, 1988.

BRASIL. Estatuto do Índio. Brasília: Senado Federal, 1973.

BRASIL. Lei $n^{\circ}$ 11.645. Altera a Lei no 9.394, de 20 de dezembro de 1996, modificada pela Lei $\mathrm{n}^{\circ} 10.639$, de 9 de janeiro de 2003, que estabelece as diretrizes e bases da educação nacional, para incluir no currículo oficial da rede 
de ensino a obrigatoriedade da temática "História e Cultura Afro-Brasileira e Indígena”. Diário Oficial da República Federativa do Brasil, Brasília, 2008.

BREMS, E.; DESMET, H. Studying Human Rights Law from the Perspective(s) of its Users. Human Rights \& International Legal Discourse, Antwerpian, v. 8, n. 2, p. 111-120, 2014.

CANDIDO, A. Formação da literatura brasileira: momentos decisivos. São Paulo: FAPESP, 2009.

CINTRA MARTINS, M. S. Inscrições, Narrativas e Literatura de produção indígena. Revista Leetra Indígena, São Carlos, v. 1, n. 1, p. 84-110, 2012.

CODATO, A.; LOBATO, T.; CASTRO, A. "Vamos lutar, parentes": as candidaturas indígenas nas eleiçōes de 2014 no Brasil. Revista Brasileira de Ciências Sociais, São Paulo, v. 32, n. 93, p. 2-24, 2017. http://doi. org/10.17666/329302/2017

COHN, S. (org.). Encontros: Ailton Krenak. Rio de Janeiro: Azougue, 2015.

CUNHA, M.C. História dos indios no Brasil. São Paulo: Companhia das Letras/Fapesp, 1992.

DESMET, E. Analysing users trajectories in Human Rights: a conceptual exploration and Research Agenda. Human Rights \& International Legal Discourse, Bruxelas, v. 8, n. 2, p. 121-141, 2014.

GRAÚNA, G. Contrapontos da literatura indígena contemporânea no Brasil. Belo Horizonte: Mazza, 2013.

HUGH-JONES, S. Escrever na pedra, escrever no papel. In: ANDRELLO, G. (org.). Rotas de criação e transformação: narrativas de origem dos povos indígenas do Rio Negro. São Paulo: ISA/FOIRN, 2012. p. 138-167.

JEKUPÉ, O. Literatura escrita pelos povos indígenas. São Paulo: Scortecci, 2009.

KAMBEBA, M. O movimento indígena. Entrevista concedida a Edson "Krenak" Dorneles de Andrade. Rio de Janeiro, 2018.

KAYAPÓ, P. O movimento indígena. Entrevista concedida a Edson "Krenak" Dorneles de Andrade. Rio de Janeiro, 2015.

HAK'Y, T. Sua literatura. Entrevista concedida a Edson Krenak. Rio de Janeiro, 2016.

KRENAK, A. O movimento indígena. Entrevista concedida a Edson "Krenak" Dorneles de Andrade. Rio de Janeiro, 2016. 
KUMU, U.P.; KENHIRI, T. Antes o mundo não existia: a mitologia heróica dos índios Desâna. São Paulo: Cultura, 1980.

MARIÁTEGUI, J.C. Siete ensayos de interpretación de la realidad peruana. México: Serie Popular Era, 1988.

MUNDURUKU, D. A palavra do grande Chefe. São Paulo: Global, 2007.

MUNDURUKU, D. Caravana literária promove a cultura dos povos indigenas em Manaus. 2011. Disponível em: $\leq$ http://danielmunduruku. blogspot.co.at/2011/03/caravana-literaria-promove-cultura-dos.html>. Acesso em: 3 maio 2018.

MUNDURUKU, D. O caráter educativo do movimento indígena brasileiro (1970-1990). São Paulo: Paulinas, 2008.

MUNDURUKU, D. O movimento indígena. Entrevista concedida a Edson "Krenak" Dorneles de Andrade. Rio de Janeiro, 2017.

ORGANIZAÇÃO DAS NAÇÓES UNIDAS (ONU). Declaração das Naçôes Unidas sobre os Direitos dos Povos Indígenas. Rio de Janeiro: UNIC, 2008.

ORGANIZAÇÃO INTERNACIONAL DO TRABALHO (OIT). Convenção $n^{\circ} 169$ sobre Povos Indígenas e Tribais. OIT, 2011. Disponível em: $\leq$ http:// portal.iphan.gov.br/uploads/ckfinder/arquivos/Convencao_169_OIT.pdf $>$. Acesso em: 10 jul. 2018.

PEARSON, N. Taking our culture on the road of Adam Smith. The Australian, 2011. Disponível em: shttps://www.theaustralian.com. au/opinion/taking-our-culture-on-the-road-of-adam-smith/news-story $>$. Acesso em: 20 jul. 2018.

POTIGUARA, E. Metade cara, metade máscara. São Paulo: Global, 2004.

PROUST, M. Em busca do tempo perdido. Porto Alegre: Globo, 1983.

SA, L. Rainforest literatures: Amazonian texts and Latin American culture. University of Minnesota Press: Minneapolis, 2004.

SAID, E. Orientalism. Nova York: Pantheon Books, 1978.

SANTOS, B. de S. Epistemologies of the South: justice against epistemicide. Boulder: Paradigm Publishers, 2014.

SHAWN, W. Research is ceremony: indigenous research methods. Halifax, Winnipeg: Fernwood Publishing, 2008. 
SMITH, L.T. Decolonizing methodologies: research and indigenous peoples. Nova York: Otago University Press, 2012.

SOUZA, L.M.T.M. de. Uma outra história, a escrita indígena no Brasil. In: INSTITUTO SOCIOAMBIENTAL (org.). Enciclopedia dos Povos Indigenas do Brasil. São Paulo: Instituto Socioambiental, 2008. p. 1-2.

THIÉL, J. Pele silenciosa, pele sonora: a literatura indígena em destaque. Belo Horizonte: Autêntica, 2012.

WAPICHANA, C. O movimento indígena. Entrevista concedida a Edson “Krenak" Dorneles de Andrade. Rio de Janeiro, 2016.

\section{NOTAS}

1. Nas últimas décadas tem havido muitas tendências na filosofia da educação e epistemologia científica apontando para essa direção, que talvez sejam devedoras das incursôes das ideias indígenas na sociedade não indígena, porém não me estenderei no tema.

2. Daniel Munduruku (2008) discute o caráter educativo do movimento indígena brasileiro nas décadas de 1970 a 1990.

3. Embora juristas e especialistas em direitos humanos também sejam considerados usuários dentro do aporte teórico proposto por Desmet (2014) e outros, faço um movimento de análise e aplicação um pouco mais centrípeto, restringindo a definição de usuário ao não especialista da lei, basicamente, um leigo.

4. Em outras palavras: ao invés de analisar a questáo dos direitos humanos do ponto de vista de um técnico de iluminação, que escolhe o holofote certo ou a melhor cor para iluminar a cena (inevitavelmente apresentando uma visão parcial), adota-se a posição do ator ou do músico em cena, que é simultaneamente iluminada por diferentes luzes, de diferentes perspectivas e com diferentes intensidades e cores. Trata-se de um conhecimento, portanto, "de dentro", de uma perspectiva de um insider com base na experiência de envolvimento efetivo com os direitos humanos, em vez de conhecimento produzido a partir do ponto de vista de um narrador onisciente (tradução minha).

5. Novamente, procuro distanciar-me da tipologia de usuários de Desmet (2014), para focar aqui no indígena.

6. Ver em Codato, Lobato e Castro (2017) uma interessante discussão sobre candidatos políticos indígenas.

7. Como é discutido no capítulo "Experiências interculturais no espaço da universidade: a presença dos acadêmicos indígenas e as contribuiçóes à Lei 11.645/08” (BRASIL, 2008) neste dossiê. 
8. Nesta parte as falas dos meus parentes serão introduzidas pelos seus nomes seguidos de dois-pontos. A impossibilidade de citar uma referência escrita que inexiste é clara, pois sáo resultados de conversas e anotaçôes de campo muitas vezes tomadas dentro do carro enquanto dirigíamos, num bar ou restaurante, numa escola, numa roda de conversa durante os anos de 2011 a 2016.

9. Como vimos, muitos indígenas, principalmente na região norte do país, participam da cena política local e municipal.

Recebido em 6 de fevereiro de 2019.

Aprovado em 9 de setembro de 2019. 